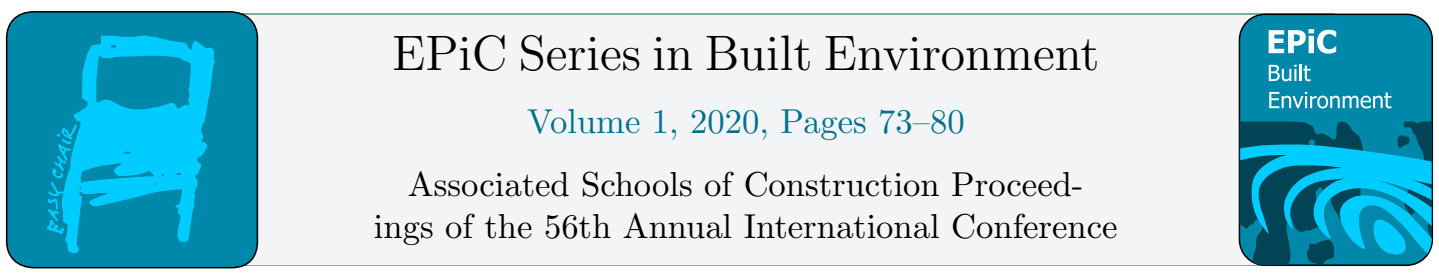

\title{
Active Learning Techniques in Understanding Risk Associated with Planning
}

\author{
Lee Templin, P.E. \\ Ferris State University \\ Big Rapids, MI
}

\author{
Richard Miller, Ph.D. \\ Ohio Northern University \\ Ada, $\mathrm{OH}$
}

\begin{abstract}
In the construction industry, projects involve a variety of techniques to communicate the project plan and the many parts associated with successful completion. While all are important elements of the project, the construction plan is a vital part of the project's success and how it is created, used, revised, and evaluated. Educators use various delivery methods in the classroom to teach planning and scheduling but the many intangibles out of the control of the scheduler make it difficult to convey all the concepts associated with these key elements of the project. Using active learning methods, such as a board game, engages the learner, introduces intangibles and promotes critical thinking and problem-solving skills for the CM student. Results from the study will provide insight into active learning and the possibilities of developing learning tools that can assist young professionals in the field. This element of instruction is paramount to the success of the new transitional student in programs across the country. Passive learning experiences no longer mimic the active projects that are prevalent in the industry today. Using the results from this study will illuminate opportunities in the classroom using active learning as a vehicle for synthesizing knowledge.
\end{abstract}

Key Words: Planning, Risk, Scheduling, Active Learning, Tasks

\section{Background}

The Project Planning Exercise is conducted during the first week of classes before the junior construction management students have been truly immersed into the planning and scheduling process. The exercise serves a dual purpose: first, the exercise exposes the student to the potential risks associated with differing levels of planning, and second, it allows the students to interact with each other in a more comfortable setting before they select their teams for the term scheduling project. This exercise has been conducted in one of the author's scheduling classes since early 2000s. The Project Planning Exercise is based on the Oops Game and was introduced to one of the authors by Dr. Gunnar Lucko of the Catholic University in Washington, D.C. This paper provides insight into the perceptions of the students participating in the exercise as well as the numerical results of the exercise. 
Managers are often placed in a difficult predicament when considering the Planning-Action dilemma. Managers confronted with this situation must decide between spending resources such as time and money to collect more information or pursuing an action at the risk of committing an enormous mistake. The managers basically must decide with two options at their disposal; act or plan. This exercise simulates the problem of choosing between acting with limited information or gathering additional information and thereby reducing risk.

\section{Literature Review}

\section{Active Learning Strategies}

Part of the draw for the Project Planning game is opening students to real world situations while using learning activities to stimulate their interest. Engaged learners in the classroom are key to the success and growth of knowledge assimilated by students in Construction Management CM programs. Strategies employed are wide ranging and include experiential learning opportunities, project-based learning, and application or goal-oriented instruction whereas activities are supported by theory and practice (Daok, Bahous, \& Bacha, 2016). In addition, (Meyers \& Jones, 2014), reported that the actual activity is second hand to the development of a student's ability to develop knowledge when actively engaged in learning experiences that promote self-awareness and objectivity for the subject. Many CM program's curricula are centered on performance within theory, or the instructional theory is placed before active learning. Meyers and Jones felt that a flipped delivery method could be more effective knowing the type of student that is drawn to programs using performance standards.

In traditional classroom settings, instruction is delivered via "instructor" driven information that is mimicked by the student at a later time. The development of activities that promote thought and action prior to information gathering from the students sheds new insight into active learning sets. Bloom's taxonomy of Learning is based on hierarchical ordering of cognitive skills that can, among countless other uses, help the student learn (Thought, 2019). The current application in this paper uses the hierarchical process but with synthesis before comprehension. In actuality, the use of pre-tests have been long thought of as a gauge of knowledge but many times randomized due to the wide ranging results at the beginning of the module or unit (Foldnes, 2016). For this application, the use of the pretest is not to gauge the knowledge of the student, but to see reaction, organization, and ability to engage in critical thinking skillsets that promote success in the construction industry.

The Oops game is used to engage the students into thinking of the consequences of their action or their lack of action. The actions available to the students are to ignore risk by doing no planning, avoid risks by planning until no risks exists, or evaluating risks by judging the possible risk before deciding. At what level of planning? Does a construction firm feel comfortable that they have mitigated the risk associated with the project. (Howell \& Liu, 2012). As learning professionals, students are afforded opportunities to gain insight through learning applications that mimic the industry. Using applications such as games, active learning activities, and measurable competencies allow faculty to gain insight into some of the strengths and weaknesses of their students while promoting a team mentality in learning.

\section{Risk and Scheduling}

An important aspect of a construction project is the action of the schedule for financial and time purposes. This activity allows students to become acquainted with repercussions associated with decision making. Scheduling, tasks, budgeting, resource loading, and risks are typical integrations 
within a construction project and many times, young professionals fail to see the magnitude of each independently as well as together. In developing the outcomes for this project, it was noted that project-based outcomes foster a sense of completion or success for the student and an ability to reflect or recall much easier than from a comprehension level (Farrow \& Rahn, 2016). With any project, the use of appropriate tools become increasingly important along with a willingness to utilize information gathered throughout. As construction professionals, the introduction and development of competencies in risk, what it is, acceptance, avoidance, or mitigation gives students a wider spectrum decision making skills in those critical thinking situations. Coble \& Coble asserted that the mitigation of risk through construction planning is vital to the success of the project and something that many young professionals struggle during the outset of their career (Coble \& Coble L, 2018). The projectactivity game in this study targets the ability of the student or team of students to develop competencies in scheduling and the risks associated with their decisions with/out prior learning engagement.

\section{Methodology}

\section{Research Questions}

Before the students engage in the Project Planning Exercise, all students will complete the PreExercise Quiz. This quiz, used as a pre-test, will be compared to the Post-Exercise Quiz to gauge the educational benefit of the Project Planning Exercise. Each student is required to complete both assessment surveys in order to gain reliable data. The educational goal of this exercise is to increase the student's awareness of how proper planning will help to mitigate potential risks associated with projects. The students are asked to engage in a pre-exercise quiz and post-exercise quiz where the twelve questions are randomized in order to not bias a question due to location in the order. The instrument uses a Likert type scale of Strongly Agree, Agree, Neutral, Disagree and Strongly Disagree. The students are given each assessment immediately before and after the Project Planning Exercise. The questions, shown below, have been validated for the assessment by multiple university faculty in the Associated Schools of Construction.

1. Planning must be performed on all projects to ensure that there are no unplanned occurrences on the project.

2. The maximum profit (or least cost) for a project is by fully planning the project to eliminate any risk.

3. Performing a project with no planning will always result in a higher cost than a fully planned project.

4. The best approach when planning a project is to avoid all risk by fully planning the project so that no unplanned occurrences happen on the project.

5. The best approach when planning a project is to ignore all risk by doing no planning on the project.

6. As the size and complexity of the project increases then the benefit of planning is magnified.

7. If there is a sixty percent $(60 \%)$ probability that an activity will be performed with no adverse results, then I feel confident to move forward with the activity.

8. If there is a seventy-five percent (75\%) probability that an activity will be performed with no adverse results, then I feel confident to move forward with the activity.

9. The best approach when a planning a project is to minimize the risk by evaluating the project so the probability of unplanned occurrences is reduced.

10. The cost of liquidated damages of a project has a direct correlation to how much planning must be completed on the project. 
11. Games are an excellent method to teach certain principles of different and confusing materials or concepts.

12. Games are a waste of time and do not help to teach any different or confusing materials or concepts.

Secondly, the other research component of this exercise is to determine which scenario provides the student groups a better score and the importance of their score to the rest of the class. This allows students to expand their understanding from a static position, to one of alternative avenues that can be explored. In doing this, student gain valuable experience in assessing solutions, determining feasibility, and action steps to be taken.

\section{Exercise Rules}

The required materials for the exercise are: nine cards numbered 1 through 9 (regular poker cards can be used), Project Planning Exercise Board and Project Planning Exercise Scorecards. The Project Planning Exercise Board is shown below:

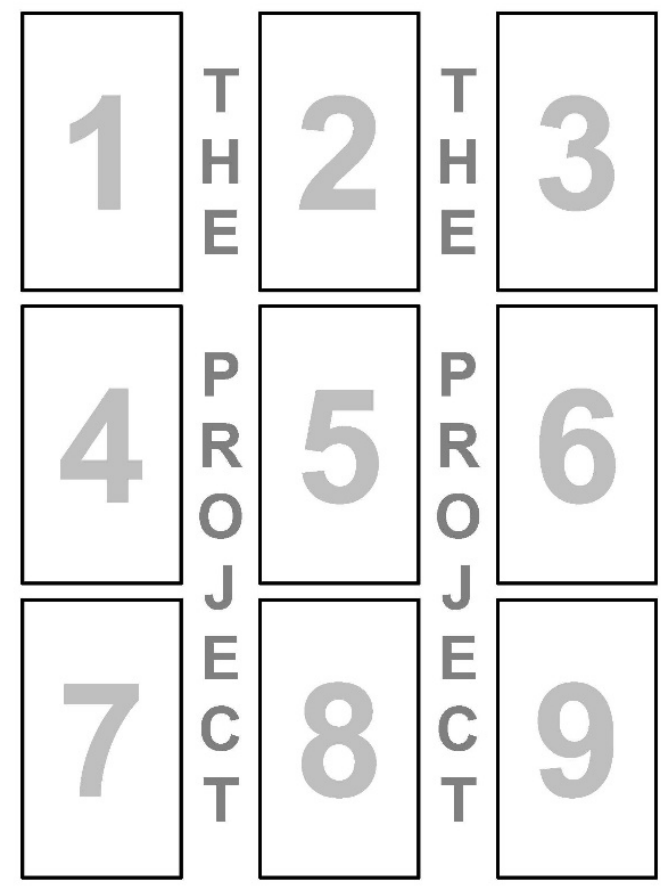

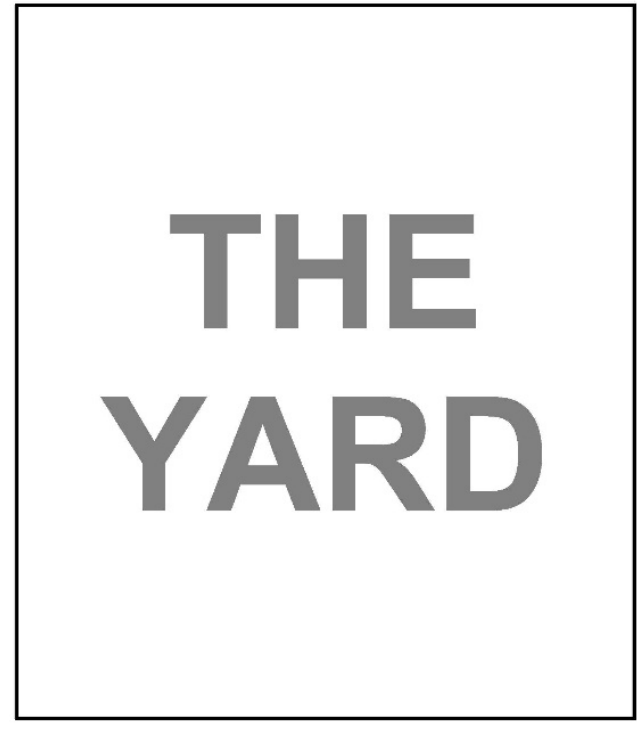

The Project PLANNING Exercise Board

Figure 1 Project Planning Exercise Board 


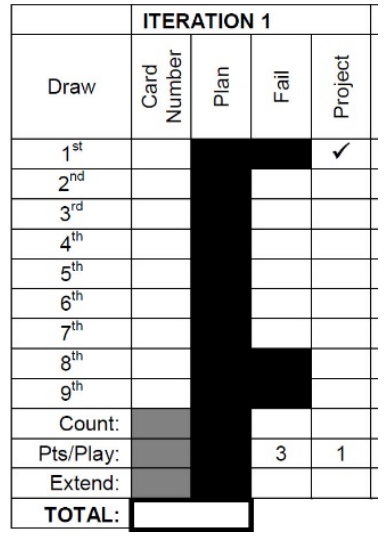

Risk Ignored

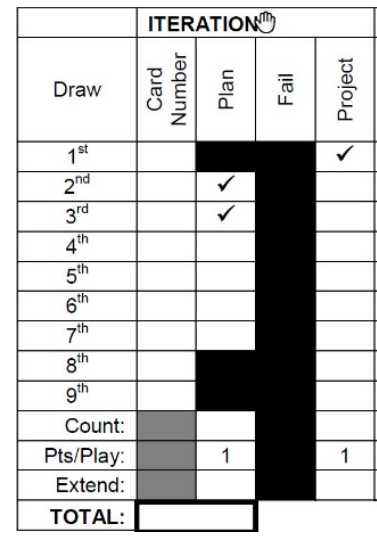

Risk Avoided

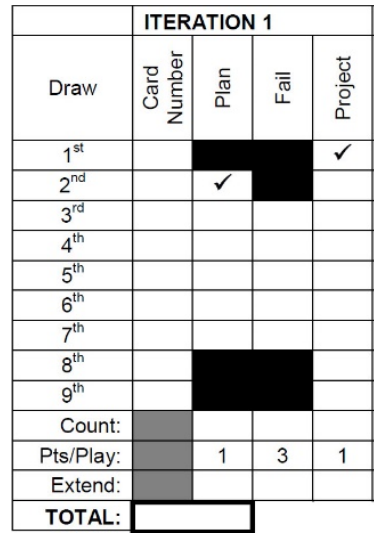

Risk Evaluated

Figure 2 Project Planning Exercise Scorecards

The objective is to assemble the PROJECT from nine cards for the lowest cost in points. In order to understand the risk associated with the exercise, there are three scenarios: Ignore Risk, Avoid Risk and Evaluate Risk, that the students will need to complete. Under each scenario, the project is constructed by picking one card at a time from THE YARD and placing the card in THE PROJECT. All cards in THE YARD are face down. Only cards that have an adjacent edge to the face up card(s) on THE PROJECT can be played face up on THE PROJECT. An adjacent edge is a card that can be placed horizontally or vertically next to a played card on THE PROJECT, for example: a 2 or 4 would be adjacent to a 1; a 1, 3 or 5 would be adjacent to a 2 ; and a 2,4,6, or 8 would be adjacent to a 5 . If the decision is to act, then the card can be played (PROJECT), it is placed on THE PROJECT face up. If the card cannot be played (FAIL) the card is placed on THE PROJECT face down. If the decision is to plan, the card is first planned (PLAN) and then if the card can be played (PROJECT) it is placed on THE PROJECT face up. If the card cannot be played (PLAN) the card is placed on THE PROJECT face down.

\section{Ignore Risk Scenario}

The Ignore Risk scenario is the first to be completed and, in this scenario, there are no decisions to be made by the students, they simply turn over the first card and play it on the PROJECT at a cost of one point. They turn over the second card and determine if the card can be played (adjacent edge to exposed card), then the card is placed (PLAY) on the PROJECT face up, but if the card is a failure (FAIL) (no adjacent edge to an exposed card), then the card is placed on the PROJECT face down. Play continues through the remaining cards in the YARD. If the students play a card (adjacent edge to exposed card) and the card is then next to a card face down, the face down card can be played (turned face up). Scoring for this scenario is played (PLAY) card costs one point and a failure (FAIL) card costs three points. So, the possible scores for this scenario are 9, 12, 15, 18, 21, 24 and 27.

\section{Avoid Risk Scenario}

The Avoid Risk scenario is the second to be completed and, in this scenario, there are still no decisions to be made by the students, they simply turn over the first card and play it on the PROJECT 
at a cost of one point. The next and remaining cards must be planned at a cost of one point unless the student is $100 \%$ certain that the card drawn can only be played on the PROJECT. If the card drawn can be played (adjacent edge to exposed card), then the card is placed (PLAY) on the PROJECT face up, but if the card cannot be played (no adjacent edge to an exposed card), then the card is placed on the PROJECT face down. Play continues through the remaining cards until the probability of playing the card is $100 \%$. Scoring for this scenario is played (PLAY) card costs one point and a planning PLAN) card costs one point. So, the possible scores for this scenario are 11, 12, 13, 14 and 15.

\section{Evaluate Risk Scenario}

The Evaluate Risk scenario is the last to be completed and, in this scenario, the students must decide whether to plan or attempt to play the card before revealing the card. As in the previous scenarios, they turn over the first card and play it on the PROJECT at a cost of one point. They must plan the next card(s) at a cost of two points, one point for planning and one point for playing, until the probability of successfully playing the card is greater than fifty percent. Once the probability is over fifty percent, the students must decide to either plan or play the card before revealing the card. If the decision is to plan the card, at a cost of one point, then the card is turned over and determined if the card can be played (adjacent edge to exposed card) if the card is played (PLAY), at a cost of one point, the card is placed on the PROJECT face up, but if the card cannot be played (no adjacent edge to an exposed card), then the card is placed on the PROJECT face down. If the decision is to play the card, at a cost of one point, then the card is turned over and determine if the card can be played (adjacent edge to exposed card), if the card is played (PLAY) on the PROJECT face up, but if the card is a failure (FAIL), at a cost of three points, (no adjacent edge to an exposed card), then the card is placed on the PROJECT face down. Play continues through the remaining cards in the YARD. If the students play a card (adjacent edge to exposed card) and the card is then next to a card face down, the face down card can be played (turned face up). Scoring for this scenario is played (PLAY) card costs one point and a failure (FAIL) card costs three points. So, the possible scores for this scenario range are $10,11,12,13,14,15,16,17,18$ and 19 .

\section{Results}

After conducting this exercise for the past ten years, the results of the scores for the three different scenarios are listed in the table below:

Table 1

Project Planning Exercise Results of the Three Differing Scenarios

\begin{tabular}{lccc}
\hline \multicolumn{1}{c}{ Scenario } & Risk Ignored & Risk Avoided & Risk Evaluated \\
\hline Mean Score & 15.8 & 13.8 & 13.2 \\
Standard Deviation & 4.3 & 1.4 & 1.8 \\
\hline
\end{tabular}

The results of the Pre-Exercise and Post-Exercise quizzes provided an inconclusive probe into the student's perception of planning and risk. Of the twelve questions on the quizzes, only two results appeared to noticeably change values. The question, "If there is a sixty percent $(60 \%)$ probability that an activity will be performed with no adverse results, then I feel confident to move forward with the activity", had a lower score on the Post-Exercise Quiz compared to the Pre-Exercise Quiz. The reason 
for the change in this score could be that some of the groups experienced an adverse outcome even though the probability of success was at sixty percent or higher when then decided to play it in the third scenario and they failed. The other question that had a noticeable change in value was "The best approach when planning a project is to avoid all risk by fully planning the project so that no unplanned occurrences happen on the project." After conducting the evaluating risk portion of the exercise, these students decided that it was best to look at the level of potential risk before deciding to plan.

\section{Discussion}

As a follow on to this initial research, the authors are expanding the opportunities for other $\mathrm{CM}$ or $\mathrm{CM}$ type programs to engage the Oops game into their own scheduling curricula. By doing so, the authors hope to increase the research agenda by including more universities. Not only will this generate tighter results, it will increase the visibility of risk planning within scheduling.

Improvements are being investigated and one of the authors has experimented with increasing the number of cards from nine to twenty-five cards and even to forty-nine cards. An exercise with this many cards could not be conducted during a two-hour lab session with the students. However, the results of the scoring for the different scenarios for the few times that the author has conducted that exercise has been staggering. Additional opportunities may be to change the cost of failure from a constant three points to random number between 1 and 6,2 and 12 or 0 and 9 . This could be accomplished by rolling a die or pair of dice after every failure, possibly a custom-made die for the game. The randomness of the cost of failure would be a representation of real life as not all failures cost the project the same amount of money.

For now, the initial research for the Project Planning Exercise provides the authors an excellent method to actively engage their students with an introduction to the risk associated with varying levels of planning and introduce active learning measures that are prevalent in any team setting.

\section{References}

Coble, L., \& Coble L. (2018). "Real Construction Mitigation Case Studies" Collaborative Risk through Construction Planning and Scheduling. Bingley, U.K.: Emerald Group Publishing.

Daok, Z., Bahous, R., \& Bacha, N. (2016). Perceptions on the Effectiveness of active learning strategies. Journal of Applied Research in Higher Education, 360-375.

Farrow, B., \& Rahn, K. (2016). How is a Construction Curriculum Built from a Set of Learning Outcomes? Proceeding from 52nd Associated Schools of Construction. Provo, Utah: ASC.

Foldnes, N. (2016). The Flipped Classroom and Cooperative Learning: Evidence in randomized experiment. Active Learning in Higher Education, 87-99.

Howell, G. \& Liu, M. (2012). The Oops Game: How Much Planning is Enough? Proceedings from the $20^{\text {th }}$ Annual Conference of the International Group for Lean Construction.

Meyers, C., \& Jones, T. (2014). Promoting Active Learning. Strategies for the College Classroom. Journal of Higher Education, 114-123. 
Thought, T. (2019, September 19). What is Bloom's Taxonomy? Retrieved from Teach Thought: https://www.teachthought.com/learning/what-is-blooms-taxonomy-a-definition-for-teachers/ 